Original Paper

\title{
Diseminasi Perbandingan Produksi Rumput Laut Menggunakan Teknologi Metode Rakit dan Long line di Teluk Ekas Lombok Timur
}

\author{
Sunarpi ${ }^{1 *}$, Eka S. Prasedya ${ }^{1}$, Ahmad Jupri1 ${ }^{1}$, Anggit L. Sunarwidhi ${ }^{2}$, Ari Hernawan ${ }^{3}$, Bq T. \\ Khairina Ilhami ${ }^{1}$, Angga S. Abidin ${ }^{1}$, Sri Widyastuti ${ }^{4}$. \\ ${ }^{1}$ Pusat Unggulan Biosains dan Bioteknologi FMIPA, Universitas Mataram, Mataram, Indonesia \\ ${ }^{2}$ Program Studi Farmasi, Fakultas Kedokteran Universitas Mataram, Mataram, Indonesia \\ ${ }^{3}$ Fakultas Teknik, Universitas Mataram, Mataram, Indonesia \\ ${ }^{4}$ Fakultas Teknologi Pangan dan Agroindustri, Universitas Mataram, Mataram, Indonesia.
}

DOI: $10.29303 /$ jpmpi.v3i2.486

Sitasi: Sunarpi, S., Prasedya, E., Jupri, A., Sunarwidhi, A., Hernawan, A., Ilhami, B., Abidin, A., \& Widyastuti, S. (2020). Diseminasi Perbandingan Produksi Rumput Laut Menggunakan Teknologi Metode Rakit dan Long line di Teluk Ekas Lombok Timur. Jurnal Pengabdian Magister Pendidikan IPA, 3(2). doi:https://doi.org/10.29303/ipmpi.v3i2.486

${ }^{*}$ Corresponding Author: Sunarpi, Pusat Unggulan Biosains dan

Bioteknologi FMIPA, Universitas Mataram, Mataram, Indonesia; Email: ekajp@yahoo.com

\begin{abstract}
Abstrak: Rumput laut yang dikenal dengan nama ilmiah makroalga merupakan salah satu komoditi bernilai ekonomi tinggi karena kandungan senyawa hidrokoloid seperti karaginan dan agar. Rendahnya kadar senyawa hidrokoloid yang dihasilkan rumput laut menyebabkan rendahnya harga jual komoditi tersebut. Sistim teknologi budidaya yang digunakan menentukan kualitas rumput laut yang dihasilkan. Artikel ini melaporkan diseminasi teknologi budidaya Eucheuma cottonii dan Eucheuma striatum sistim rakit apung dan long line kepada pembudidaya rumput laut di Teluk Ekas Lombok Timur untuk memacu peningkatan hasil rumput laut baik secara kuantitas maupun kualitas. Diseminasi teknologi dengan dua metode tanam, rakit apung dan long line, dilakukan bersama pembudidaya rumput laut di Teluk Ekas. Diseminasi teknologi yang dibarengi dengan praktek langsung, dapat melihat langsung hasil yang diperoleh dengan penerapan telnologi tersebut, yang pada akhirnya pembudidaya rumput laut mudah memahami dan secara sadar dapat meniru teknologi budidaya tersebut pada musim tanam berikutnya. Dengan demikian, diseminasi teknologi tersebut dapat meningkatkan mutu hasil, harga jual, yang pada akhirnya meningkatkan pendapatan pembudidaya.
\end{abstract}

Kata Kunci: Diseminasi; budidaya; Eucheuma cottonii; Eucheuma striatum; long line.

\section{Pendahuluan}

Rumput laut yang secara saintifik dikenal dengan nama makroalga, merupakan salah satu komoditi laut yang bernilai ekonomi tinggi. Hal ini disebabkan karena rumput laut memproduksi senyawa hidrokoloid, seperti karaginan, agar dan alginat, yang merupakan bahan baku penting berbagai industri, seperti industri pangan, farmasi dan pertanian (Suparmi dan Sahri, 2009; Maharany et al., 2017; Sunarpi et al., 2019). Atas dasar 
kenyataan itu, tahun 2005 Kementrian Kelautan dan perikanan, memasukkan komoditi tersebut sebagai salah satu program revitalisasi kekuatan ekonomi Indonesia (Hidayat dan Safitri 2019). Dengan pemikiran yang sama, pemerintah Provinsi Nusa Tenggara Barat memasukkan rumput laut sebagai salah satu komponen program PIJAR (sapi, jagung dan rumput laut) (Gunawan et al., 2013; Radiarta dan Erlania, 2015).

Nusa Tenggara Barat (NTB) dikenal sebagai salah satu daerah produksi rumput laut di Indonesia bersama Sulawesi Selatan, dengan andalan sentra produksi Teluk Ekas, Gerupuk dan Teluk Saleh. Namun demikian, sejak lima tahun terakhir, ada pergeseran aktivitas ekonomi pembudidaya rumput laut menjadi penangkap benih lobster karena lebih menjanjikan. Akibatnya di beberapa lokasi sentra produksi tidak lagi menjadi budidaya rumput laut sebagai aktivitas ekonomi utama. Namun demikian, akibat adanya keputusan Menteri Kelautan dan Perikanan RI yang melarang penangkapan benih lobster, maka aktivitas ekonomi beralih menjadi aktivitas pembesaran lobster menggunakan sistem karamba.

Mengingat pembesaran lobster dengan sistem karamba membutuhkan waktu satu tahun untuk menghasilkan, maka ada sebagian kembali berbudidaya rumput laut secara total, dan ada juga sebagian yang mengkombinasikan aktivitas pembesaran lobster dengan karamba dan budidaya rumput. Hal ini disebabkan karena budidaya rumput laut umurnya lebih pendek (39-45 hari) (Widyastuti, 2010) dan lebih cepat menghasilkan, serta lebih cepat mendapatkan uang untuk memenuhi kebutuhan sehari-hari.

Selain argumentasi di atas, rumput laut juga memiliki pasar pada berbagai level pertumbuhannya. Saat berumur 2 minggu (14 hari), rumput laut sudah punya pasar, pembudidaya bisa menjualnya sebagai bibit rumput laut. Saat berumur 30 hari, rumput laut juga sudah punya pembeli untuk dijadikan bahan pangan seperti permen, dodol, dan lainlain. Saat berumur lebih tua (45 hari) dengan asumsi telah terjadi penimbunan karaginan secara sempurna, rumput laut bisa dijual dengan harga yang lebih mahal yang dapat mencapai 20.000-22.000 rupiah per kilogram berat kering. Selain alasan di atas, rumput laut menjadi pilihan masyarakat pesisir, karena aktivitas kerja rumput laut bersifat padat karya, semua keluarga (ayah, istri dan anak) ikut serta dalam aktivitas ekonomi tersebut. Dengan demikian, aktivitas tersebut memberikan jaminan penghasilan bagi keluarga.

Pembudidaya rumput laut di Teluk Ekas yang baru mulai melakukan aktivitas ekonomi ini dihadapkan pada persoalan biaya produksi, disamping pada persoalan mutu produk yang masih rendah, dengan harga jual sekitar 12.000-13.000 rupiah per kilogram rumput laut kering. Budidaya rumput laut dengan metode rakit apung membutuhkan biaya rakit dan tali ris yang cukup mahal bagi ukuran pembudidaya, sekitar 500.000 rupiah per unit. Hasil produksi dengan metode ini sekitar 4 kali lipat dari berat awal bibit. Selain hasil yang tidak begitu tinggi, rendemen yang didapat setelah dikeringan sekitar $12-13 \%$. Kondisi ini tentu menurunkan pendapatan bagi pembudidaya.

Persoalan lain bagi metode rakit adalah masa tahan untuk bisa dipakai oleh pembudidaya rumput laut paling lama satu tahun. Dengan memperhatikan hasil yang diperoleh dengan sistim rakit yang demikian kecil, menjadi sulit bagi pembudidaya untuk bisa mengembalikan investasinya pada tahun berikutnya. Kelayakan usaha rumput laut dengan sistim rakit membutuhkan minimal 10 rakit, sekitar 5.000.000 rupiah, suatu jumlah investasi yang sulit untuk bisa dikembalikan oleh pembudidaya rumput laut. Dengan kondisi seperti itu, sudah bisa dipastikan bahwa usaha rumput laut dengan sistim rakit tidak bisa berlanjut pada musim tanam tahun berikutnya.

Atas dasar pertimbangan di atas, diperlukan perbandingan metode tanam rumput laut di Teluk Ekas, metode rakit apung menjadi metode tali panjang (long line). Metode tali panjang yang biaya investasinya tidak jauh 
beda dengan biaya rakit apung, memiliki masa tahan yang lebih panjang, minimal 5 tahun. Berdasarkan yang dikemukakan di atas, artikel ini melaporkan diseminasi perbandingan produksi rumput laut menggunakan teknologi metode rakit dan tali panjang (long line) di Teluk Ekas, Lombok Timur. Diseminasi teknologi ini melibatkan pembudidaya secara langsung, sehingga pembudidaya bisa langsung memahami dan menyadari kelebihan dan kekurangan kedua metode tersebut. Hasil pengabdian ini menunjukkan bahwa budidaya Eucheuma cottonii dan Eucheuma striatum dengan metode rakit menghasilkan rumput laut yang dan lebih berat dan dengan rendemen yang lebih tinggi dibandingkan dengan metode long line.

\section{Metode Pelaksanaan}

Diseminasi budidaya rumput laut jenis $E$. cottonii dan E. striatum metode tali panjang (long line) dengan tahapan sebagai berikut:

1) Pengikatan dan penanaman bibit rumput laut jenis E. cottonii dan E. Striatum.

Bibit rumput laut yang telah dibersihkan dari epifit diikat menggunakan tali sepanjang $100 \mathrm{~m}$ dengan berat masing-masing $100 \mathrm{gr}$ sebanyak 100 titik. Selanjutnya, bibit E. cottonii dan E. striatum di letakkan pada rakit di perairan Teluk Ekas selama 30 hari sedangkan metode tali panjang (long line) dibiarkan tumbuh selama 45 hari (Gambar 1).

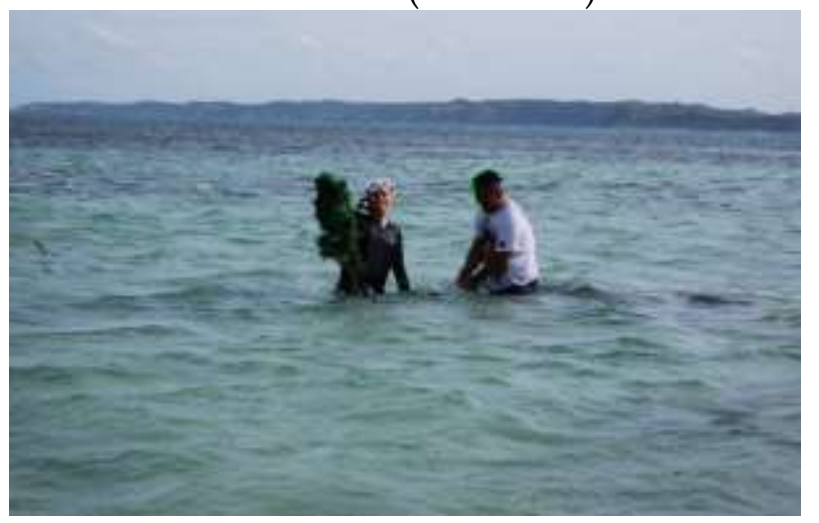

Gambar 1. Penanaman bibit rumput laut E. cottonii dan E. striatum
2) Pengamatan pertumbuhan rumput laut $E$. cottonii dan E. striatum

Pengamatan pertumbuhan rumput laut dilakukan setiap minggu selama 45 hari dengan cara mengambil sampel secara acak pada rakit dan tali panjang (long line) (Gambar 2). Berat basah rumput laut pada masing-masig metode kemudian ditimbang.

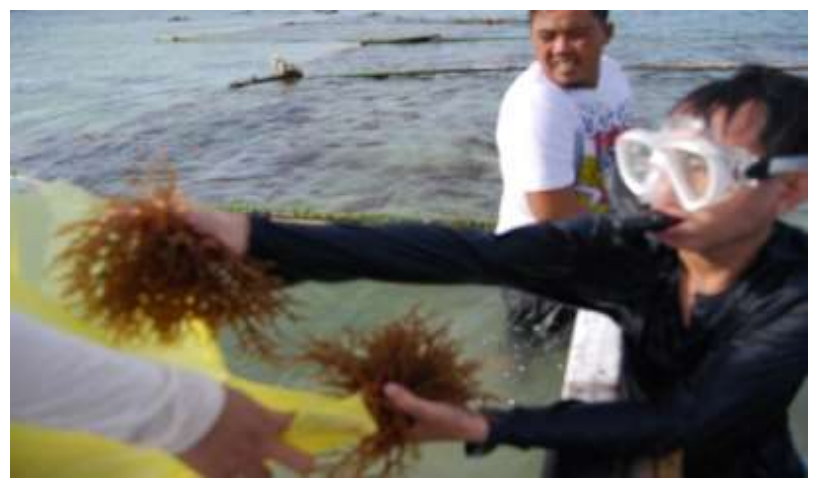

Gambar 2. Pengamatan sampel rumput laut $E$. cottonii dan E. striatum

3) Panen rumput laut

Pemanenan rumput laut dilakukan setelah berumur 30 hari pada metode rakit dan 42 hari pada metode long line (Gambar 3). Setelah dipanen rumput laut dicuci menggunakan air laut dan ditimbang. Sampel rumput laut dikeringkan menggunakan parapara selama 4-7 hari dan ditimbang berat keringnya.

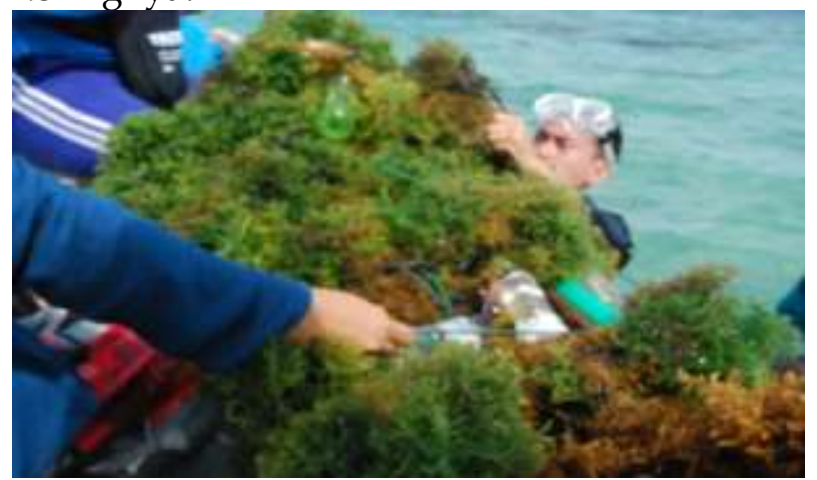

Gambar 3. Pemanenan rumput laut E. cottonii dan E. striatum

\section{Hasil dan Pembahasan}

Diseminasi budidaya rumput laut menggunakan metode rakit dan long line 
memiliki perbedaan berat basah, berat kering dan persentase rendemen pada jenis rumput laut E. cottonii dan E. striatum. Hal ini terlihat pada Tabel 1:

Tabel 1. Perbandingan berat basah, berat kering dan rendemen E. cottonii dan E. striatum

\begin{tabular}{llllllll}
\hline \multirow{2}{*}{ No } & \multirow{2}{*}{ Jenis Rumput Laut } & \multicolumn{2}{c}{ Berat Basah (gr) } & \multicolumn{2}{c}{ Berat Kering (gr) } & \multicolumn{2}{c}{ Rendemen (\%) } \\
\cline { 2 - 7 } & & Rakit & Long line & Rakit & Long line & Rakit & Long line \\
\hline 1. & E. cottonii & 492.25 & 113.16 & 44.08 & 11.90 & 9.64 & 11.24 \\
2. & E. striatum & 424.97 & 198.87 & 34.11 & 26.12 & 9.12 & 11.67 \\
\hline
\end{tabular}

Berat basah menggunakan metode rakit pada kedua jenis rumput laut memiliki berat basah 2 kali lipat dibandingkan dengan menggunakan metode long line. Metode penanaman sangat berpengaruh terhadap laju pertumbuhan rumput laut. Berat basah pada metode rakit lebih tinggi jika dibandingkan dengan metode long line karena pergerakan arus dan intesitas cahaya matahari yang tinggi sehingga rumput laut banyak menerima nutrien (Wijayanto et al., 2011). Pada long line ditemukan banyak epifit yang menyebabkan terhalangnya sinar matahari dan proses fotosintesis sehingga pertumbuhan rumput laut terganggu.

Berdasarkan data diatas, dapat diketahui kelebihan dan kekurangan dari masing-masing metode. Jika dilihat dari aspek biaya yang diperlukan untuk pembuatan alat tanam, baik rakit maupun long line memiliki biaya yang tidak jauh berbeda. Aspek yang kedua yaitu masa tahan alat. Metode rakit hanya dapat bertahan selama 1 tahun sedangkan metode long line dapat digunakan selama 5 tahun. Aspek ketiga yaitu produksi rumput laut yang dihasilkan. Pada sistem rakit, didapatkan hasil berat basah dan berat kering lebih tinggi jika dibandingkan dengan long line namun, berbeda dengan persentase rendemen yang dihasilkan. Aspek keempat yaitu kepraktisan penanaman rumput laut di laut. Metode long line lebih praktis jika dibandingkan dengan rakit.

\section{Kesimpulan}

Hasil diseminasi perbandingan produksi rumput laut diharapkan pembudidaya dapat menggunakan metode yang tepat untuk menghasilkan produksi dan kualitas rumput laut yang tinggi sehingga dapat meningkatkan harga jual dan pendapatan pembudidaya rumput laut E. cottonii dan E. striatum.

\section{Ucapan Terimakasih}

Penulis mengucapkan terimakasih kepada dewan DRIN riset dan inovasi Kemenristek RI yang telah menyediakan anggaran pengabdian masyarakat PPDM tahun 2020, rektor Universitas Mataram dan seluruh pihak yang telah berpartisipasi dan berkontribusi selama kegiatan berlangsung, terutama kelompok masyarakat pembudidaya rumput laut di Teluk Ekas, Lombok Timur.

\section{Daftar Pustaka}

Gunawan, E.R., Suhendra, D., \& Hermanto, D. (2013). Optimalisasi Integrasi Sapi, Jagung, dan Rumput Laut (Pijar) pada Teknologi Pengolahan Pakan Ternak Berbasis Limbah Pertanian Jagung-Rumput Laut Guna Mendukung Program Bumi Sejuta Sapi (BSS) di Nusa Tenggara Barat. Buletin Peternakan. 37(3): 157-164.

Hidayat, A., \& Safitri, P. (2019). Pengembangan Komoditas Rumput Laut Nusa Tenggara Barat dengan Model Hexagon untuk Pembangunan Ekonomi Lokal. Jurnal Kebijakan Sosek KP. 9(1): 45-55.

Maharany, F., Nurjanah, S.R, Anwar, E., \& Hidayat, T. (2017). Kandugan Senyawa Bioaktif Rumput Laut Padina australis dan Eucheuma cottonii sebagai Bahan Baku Krim Tabir Surya. Jurnal Pengolahan Hasil Perikanan Indonesia. 20(1): 10-17. 
Radiarta, I.N., \& Erlania. (2015(. Indeks Kualitas Air dan Sebaran Nutrien Sekitar Budidaya Rumput Laut Terintegrasi di Perairan Teluk Ekas, Nusa Tenggara Barat Aspek Penting Budidaya Rumput Laut. Jurnal Riset Akuakultur. 10(1): 141-152.

Sunarpi., Pebriani, S.A., Yogi, A., Putri, F.E, Nikmatullah, A., Ghazali, M., Kurnianingsih, R., \& Prasedya, E.S. (2019). Effect of Inorganic Fertilizer and Brown Alga Solid Extract on Growth and Yield of Rice Plants. AIP Conference Proceeding 2199(1): 1-5.

Suparmi \& Sahri, A. (2009). Mengenal Potensi Rumput laut: Kajian Pemanfaatan Sumber Daya Rumput Laut dari Aspek Industri dan Kesehatan. Sultan Agung. XLIV (118): 95-116.

Widyastuti, S. (2010). Sifat Fisik dan Kimiawi Karagenan yang Diekstrak dari Rumput Laut Eucheuma cottonii dan E. spinosum pada Umur Panen yang Berbeda. Jurnal Agroteksos. 20(1): 41-50.

Wijayanto, T., Hendri, M., \& Aryawati, R. (2011). Studi Pertumbuhan Rumput Laut Eucheuma cottonii dengan Berbagai Metode Penanaman yang berbeda di Perairan Kalianda, Lampung Selatan. Maspari Journal. 3: 51-57. 